\title{
ACETABULAR COMPONENT ORIENTATION IN TOTAL HIP ARTHROPLASTY: THE ROLE OF ACETABULAR TRANSVERSE LIGAMENT
}

\author{
Mohammed El Idrissi ${ }^{1}$, Abdelhalim Elibrahimi ${ }^{1}$, Mohammed Shiml ${ }^{1}$, Abdelmajid Elmrini ${ }^{1}$ \\ 1. Hassan II University Hospital, Orthopedics Department, Fez, Morocco.
}

\section{ABSTRACT}

Objective: The aim of our study is to present the benefit of using the transvers acetabular ligament for intraoperative determination of the anteversion of acetabular component. Methods: Twenty-one total hip arthroplasties were performed. The transverse acetabular ligament was identified and used as a guide to position the acetabular component. Results: The mean anteversion angle was 16.9. None of the patients studied sustained a postoperative dislocation during this short follow-up period. Conclusion: We conclude from this preliminary study that the transverse acetabular ligament can aid positioning of the acetabular component of a THR. It defines the version of the acetabular component without the need for external instrumentation, and is independent of the position of the patient. Level of Evidence IV; Prospective Study.

Keywords: Hip, Arthroplasty, Hip dislocation.

Citation: El Idrissi M, Elibrahimi A, Shimi M, Elmrini A. Acetabular component orientation in total hip arthroplasty: the role of acetabular transverse ligament. Acta Ortop Bras. [online]. 2016;24(5):267-9. Available from URL: http://www.scielo.br/aob.

\section{INTRODUCTION}

Acetabular cup positioning has a significant effect on the outcome of total hip arthroplasty (THA). It affects dislocation rate, component impingement, edge loading, accelerated bearing surface wear and osteolysis and/or loosening. In the course of surgery, the most important step is cup orientation. The position on the operating table, dislocation of the native hip and the use of retractors alter the pelvis and, thus, acetabular version. ${ }^{2}$ Several methods have been described in the literature and several devices are available from THA prosthesis manufacturers to help correct cup placement. Many authors have described the transverse acetabular ligament (TAL) as a patient-specific reference point in determining the correct acetabular anteversion. The aim of our study is to resent the benefit of using the transvers acetabular ligament for intraoperative determination of the anteversion of acetabular component.

\section{MATERIAL AND METHODS}

A retrospective study was conducted between January 2013 and January 2015. It included 21 total hip arthroplasties performed by two senior surgeons. Ten patients were operated for hip osteoarthritis, eight for femoral neck fracture, and three for coxitis. Each patient had a postoperative anteroposterior (AP) radiograph of the pelvis, which was used to measure the abduction angle of the acetabular cup from lines drawn through the face of the cup and the inter-teardrop line. A standardized crosstable true lateral view of the hip was taken with the patient supine on the radiographic table with the contralateral lower extremity flexed as much as possible to eliminate lumbar lordosis and place the pelvis in a standard position. The anteversion angle of the acetabular component was measured according to the technique of Woo. ${ }^{3}$

\section{Surgical technique}

Minopen posterior approach was used. (Figure 1) The piriformis tendon was preserved in all patients. As described by Archbold, retractors were used to obtain full exposure of the acetabulum. Inferiorly, the retractor was placed in a way that the transverse acetabular ligament remained superficial to it. The appearance of this ligament was graded using Archbold's classification. ${ }^{4}$ (Table 1) Once defined, (Figure 2) the transverse acetabular ligament was used as a guide to acetabular reaming. Then, the ligament embraced the final acetabular reamer and thereby, the acetabular component. (Figure 3)

The Hospital Ethics Committee approved the study, and all patients signed a Free and Informed Consent form before the surgery.

\section{RESULTS}

The transverse acetabular ligament was identified and exposed in all cases. Radiological results are shown in Table 2. The mean anteversion angle was $16.9^{\circ}$. None of the patients studied showed a postoperative dislocation during the short follow-up period.

All the authors declare that there is no potential conflict of interest referring to this article. 


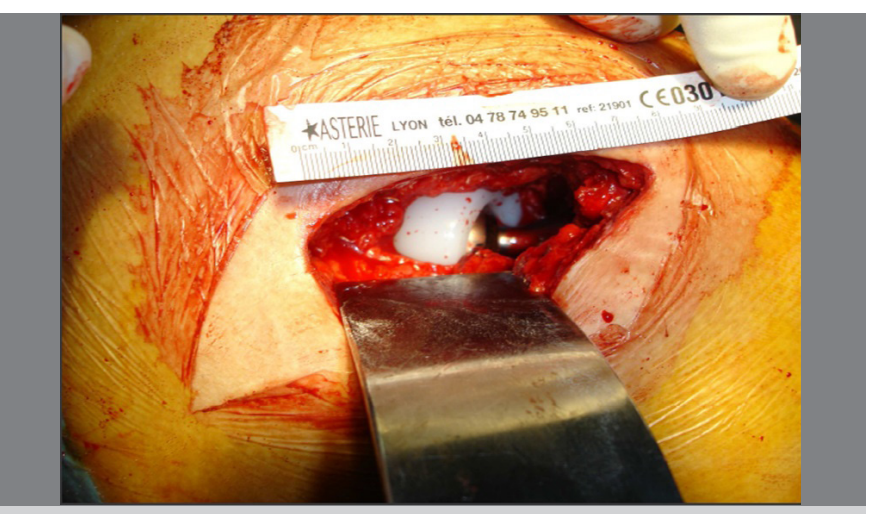

Figure1. Posterior miniopen surgical approach.

\begin{tabular}{|c|c|}
\hline Grade of ATL & Appearance of ATL visualized during THA \\
\hline 1 & Normal quality ATL visible at the acetabulum exposure \\
\hline 2 & $\begin{array}{c}\text { ATL covered by soft tissue which has to be removed to } \\
\text { expose the ligament }\end{array}$ \\
\hline 3 & $\begin{array}{l}\text { ATL covered by osteophytes which have to be removed } \\
\text { to expose the ligament }\end{array}$ \\
\hline 4 & $\begin{array}{l}\text { Ligament not identified, even after proper removal of } \\
\text { osteophytes or soft tissue }\end{array}$ \\
\hline
\end{tabular}

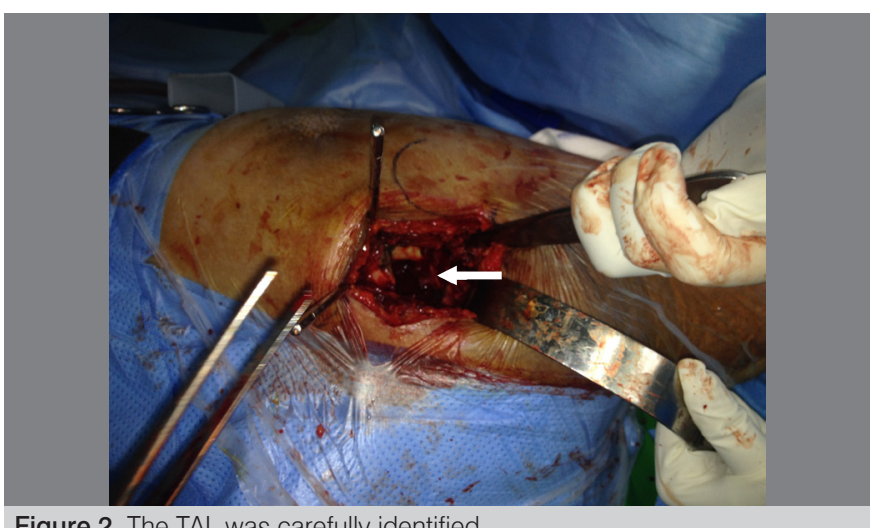

Figure 2. The TAL was carefully identified.

\section{DISCUSSION}

Positioning of the acetabular component in THA has been shown to affect the range of motion of the hip, wear of the polyethylene, and the rate of pelvic osteolysis, being of paramount importance in minimizing the risk of dislocation. ${ }^{5-8}$ Unlike inclination, which according to most authors should be approximately $45^{\circ} 6,9-11$ there is no consensus about how much anteversion is needed for the acetabular cup. Murray ${ }^{12}$ has defined three types of cup anteversion: anatomical, operative and radiographic. Anteversion values may differ depending on the plane of reference, and Murray has developed conversion nomograms for these three definitions. Lewinnek et al. ${ }^{7}$ described a 'safe zone' for acetabular anteversion as being $15 \pm 10^{\circ}$, using a posterolateral approach. In the course of surgery, the most important step is cup orientation. The position on the operating table, the dislocation of the native hip and the use of retractors may alter the pelvis and, thus, the acetabular version. ${ }^{12}$ Several methods have been described in the literature and several devices

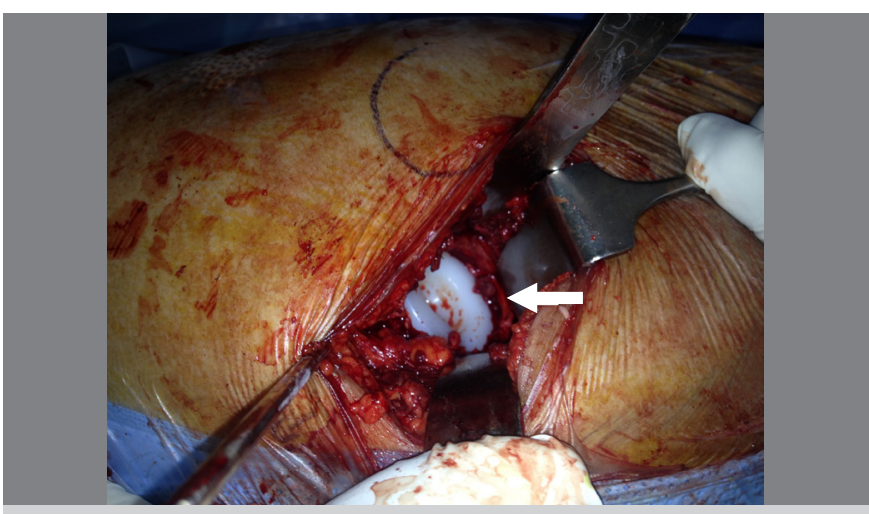

Figure 3. The TAL embraces the acetabular component.

Table 2. Radiological results.

\begin{tabular}{c|c|c|c}
\hline Patient & Diagnosis & $\begin{array}{c}\text { Anteversion angle } \\
\text { (degrees) }\end{array}$ & $\begin{array}{c}\text { Abduction angle } \\
\text { (degrees) }\end{array}$ \\
\hline P1 & hip osteoarthritis & 11 & 38 \\
\hline P2 & hip osteoarthritis & 15 & 30 \\
\hline P3 & hip osteoarthritis & 9 & 35 \\
\hline P4 & hip osteoarthritis & 8 & 41 \\
\hline P5 & hip osteoarthritis & 28 & 40 \\
\hline P6 & hip osteoarthritis & 18 & 43 \\
\hline P7 & hip osteoarthritis & 13 & 48 \\
\hline P8 & hip osteoarthritis & 15 & 37 \\
\hline P9 & hip osteoarthritis & 27 & 35 \\
\hline P10 & hip osteoarthritis & 16 & 45 \\
\hline P11 & Fracture of the femoral neck & 21 & 33 \\
\hline P12 & Fracture of the femoral neck & 15 & 32 \\
\hline P13 & Fracture of the femoral neck & 25 & 39 \\
\hline P14 & Fracture of the femoral neck & 24 & 32 \\
\hline P15 & Fracture of the femoral neck & 18 & 42 \\
\hline P16 & Fracture of the femoral neck & 20 & 44 \\
\hline P17 & Fracture of the femoral neck & 21 & 43 \\
\hline P18 & Fracture of the femoral neck & 16 & 48 \\
\hline P19 & Coxitis & 16 & 46 \\
\hline P20 & Coxitis & 18 & 45 \\
\hline P21 & Coxitis & 16 & 41 \\
\hline Mean (SD) & & $16.9( \pm 5)$ & $39.85( \pm 5)$ \\
\hline & & & \\
\hline & & & \\
\hline & & & 45 \\
\hline
\end{tabular}

are available from THA prosthesis manufacturers to help cup correct placement. ${ }^{13-15}$ Many studies have recommended the use of the triangular acetabular ligament (TAL) for acetabular component positioning. ${ }^{4,16-19}$ Although navigation technology has been shown to significantly improve precision during insertion of the acetabular component, the additional cost and increased duration of surgery has prevented the widespread uptake of these techniques. ${ }^{20,21}$ Furthermore, considering the variation in the patients' anatomy and their functional pelvic tilt, one might question the necessity of achieving standard acetabular implant orientation in every patient. In order to achieve a reliable and patient-specific alignment, there is a need for technical aids and tools base on reproducible anatomical landmarks. ${ }^{22}$

Archbold et al. ${ }^{4}$ have introduced the use of the TAL as a patient-specific reference point in determining the correct acetabular anteversion. With a large sample size, the TAL was easily identified in most cases and a very low rate of dislocation was observed. These authors present an easily reproducible and valid technique which is of widespread use today. 
In order to assess the influence of acetabular component alignment relative to TAL and the posterior labrum as soft-tissue landmarks, Kalteis et al. ${ }^{23,24}$ measured the orientation of the native acetabular plane as defined by the transverse acetabular ligament and the posterior labrum intra-operatively, using computer-assisted navigation. They suggest that this alignment can reduce malpositioning of the acetabular component in total hip replacement according to the traditional safe zones. However, there is no improvement in range of movement and no decrease in impingement in an anatomical orientation when the acetabular component is aligned to the TAL and the posterior labrum, as compared to a standard orientation at $45^{\circ}$ of abduction and $15^{\circ}$ of anteversion. Viste et al..$^{25}$ suggested that that cup orientation should be specific for each patient and not a universal standard, as suggested by Lewinnek et al. ${ }^{7}$ Indeed, anteversion is not a static parameter, but a specific dynamic value for each individual. According to Archbold et al., ${ }^{4}$ this technique may not be applicable where a significant acetabular structural abnormality is present, as in severe dysplasia or following a pelvic fracture.

In our study, we had no case of hip dislocation. The TAL was easily identified in all patients. However, a larger and comparative study is needed to confirm this results.

\section{CONCLUSION}

We conclude from this preliminary study that the transverse acetabular ligament can assist to position the acetabular component in THR. It defines the degree of version of the acetabular component without the need for external instrumentation, and it is independent of the patient's position.

AUTHORS' CONTRIBUTIONS: Each author contributed individually and significantly to the development of the study. MEl (0000-0003-0104$389 \mathrm{X})^{\star}$ was the main contributor in writing the manuscript. $\mathrm{AE}$ conducted the literature search; $\mathrm{MS}^{*}$ and $\mathrm{AE}^{*}$ reviewed the manuscript and approved the final version. All authors contributed to the intellectual concept of the study. ${ }^{*}$ ORCID (Open Researcher and Contributor ID).

\section{REFERENCES}

1. Meftah M, Yadav A, Wong AC, Ranawat AS, Ranawat CS. A novel method for accurate and reproducible functional cup positioning in total hip arthroplasty. J Arthroplasty. 2013;28(7):1200-5.

2. Biedermann R, Tonin A, Krismer M, Rachbauer F, Eibl G, Stöckl B. Reducing the risk of dislocation after total hip arthroplasty: the effect of orientation of the acetabular component. J Bone Joint Surg Br. 2005;87(6):762-9.

3. Woo RY, Morrey BF. Dislocations after total hip arthroplasty. J Bone Joint Surg Am. 1982;64(9):1295-306.

4. Archbold HA, Mockford B, Molloy D, McConway J, Ogonda L, Beverland D. The transverse acetabular ligament: an aid to orientation of the acetabular component during primary total hip replacement: a preliminary study of 1000 cases investigating postoperative stability. J Bone Joint Surg Br. 2006;88(7):883-6.

5. Kummer FJ, Shah S, lyer S, DiCesare PE. The effect of acetabular cup orientations on limiting hip rotation. J Arthroplasty. 1999;14(4):509-13.

6. Patil S, Bergula A, Chen PC, Colwell CW Jr, D'Lima DD. Polyethylene wear and acetabular component orientation. J Bone Joint Surg Am. 2003;85(Suppl 4):56-63.

7. Lewinnek GE, Lewis JL, Tarr R, Compere CL, Zimmerman JR. Dislocations after total hip-replacement arthroplasties. J Bone Joint Surg Am. 1978;60(2):217-20.

8. Kennedy JG, Rogers WB, Soffe KE, Sullivan RJ, Griffen DG, Sheehan LJ. Effect of acetabular component orientation on recurrent dislocation, pelvic osteolysis, polyethylene wear, and component migration. J Arthroplasty. 1998;13(5):530-4.

9. Schmalzried TP, Guttmann D, Grecula M, Amstutz HC. The relationship between the design, position, and articular wear of acetabular components inserted without cement and the development of pelvic osteolysis. J Bone Joint Surg Am. 1994;76(5):677-88.

10. Dorr LD, Wolf AW, Chandler R, Conaty JP. Classification and treatment of dislocations of total hip arthroplasty. Clin Orthop Relat Res. 1983;(173):151-8.

11. McCollum DE, Gray WJ. Dislocation after total hip arthroplasty. Causes and prevention. Clin Orthop Relat Res. 1990;(261):159-70.

12. Murray DW. The definition and measurement of acetabular orientation. J Bone Joint Surg Br. 1993;75(2):228-32.

13. Murtha PE, Hafez MA, Jaramaz B, DiGioia AM 3rd. Variations in acetabular anatomy with reference to total hip replacement. J Bone Joint Surg Br. 2008;90(3):308-13.

14. Doyle J, Farmer MH, Shepard G. Device for accurately siting the aceta- bular component during total hip replacement. Arch Orthop Trauma Surg 2002;122(9-10):554-6.

15. Digioia AM 3rd, Jaramaz B, Plakseychuk AY, Moody JE Jr, Nikou C, Labarca $\mathrm{RS}$, et al. Comparison of a mechanical acetabular alignment guide with computer placement of the socket. J Arthroplasty. 2002;17(3):359-64.

16. Doyle J, Murray P, Mahony PO, Farmer M, Hooper AC. Acetabular cup-siting device for total hip arthroplasty. Arch Orthop Trauma Surg. 1989;108(5):317-21.

17. Hassan DM, Johnston GH, Dust WN, Watson G, Dolovich AT. Accuracy of intraoperative assessment of acetabular prosthesis placement. J Arthroplasty. 1998;13(1):80-4.

18. Miyoshi H, Mikami H, Oba K, Amari R. Anteversion of the acetabular component aligned with the transverse acetabular ligament in total hip arthroplasty. J Arthroplasty. 2012;27(6):916-22.

19. Archbold HA, Slomczykowski M, Crone M, Eckman K, Jaramaz B, Beverland $\mathrm{DE}$. The relationship of the orientation of the transverse acetabular ligament and acetabular labrum to the suggested safe zones of cup positioning in total hip arthroplasty. Hip Int. 2008;18(1):1-6.

20. Pearce CJ, Sexton SA, Davies DC, Khaleel A. The transverse acetabular ligament may be used to align the acetabular cup in total hip arthroplasty. Hip Int. 2008;18(1):7-10

21. Jain S, Aderinto J, Bobak P. The role of the transverse acetabular ligament in total hip arthroplasty. Acta Orthop Belg. 2013;79(2):135-40.

22. Noble PC, Sugano N, Johnston JD, Thompson MT, Conditt MA, Engh CA, et al. Computer simulation: how can it help the surgeon optimize implant position? Clin Orthop Relat Res. 2003;(417):242-52.

23. Kalteis T, Handel M, Bäthis H, Perlick L, Tingart M, Grifka J. Imageless navigation for insertion of the acetabular component in total hip arthroplasty: is it as accurate as CT-based navigation? J Bone Joint Surg Br. 2006;88(2):163-7.

24. Kalteis T, Sendtner E, Beverland D, Archbold PA, Hube R, Schuster T, et al. The role of the transverse acetabular ligament for acetabular component orientation in total hip replacement: an analysis of acetabular component position and range of movement using navigation software. J Bone Joint Surg Br. 2011;93(8):1021-6.

25. Viste A, Chouteau J, Testa R, Chèze L, Fessy MH, Moyen B. Is transverse acetabular ligament an anatomical landmark to reliably orient the cup in primary total hip arthroplasty? Orthop Traumatol Surg Res. 2011;97(3):241-5. 